\title{
Factors Affecting Disease-Free Status of Differentiated Thyroid Carcinoma Patients
}

\author{
Kanungnij Thamnirat, Chirawat Utamakul, Wichana Chamroonrat, Arpakorn \\ Kositwattanarerk, Yoch Anongpornjossakul, Chanika Sritara
}

\begin{abstract}
Purpose: The study aim was to assess factors that impact on the outcome of radioiodine therapy in patients diagnosed with differentiated thyroid carcinoma (DTC). Materials and Methods: We performed a retrospective cohort study on 256 patients with DTC who underwent thyroidectomy and received radioiodine therapy during December 2003 to January 2012. All patients were followed up for at least 1 year. They were considered diseasefree by the criteria of the revised American Thyroid Association Management Guideline for Patients with Thyroid nodules and DTC (ATA guideline 2009). Results: On Cox univariate analysis, factors associated with disease-free status were age $<45$, stage I tumor, low risk group by histopathology, unifocal tumor involvement, stimulated serum Tg level at 1st dose of radioiodine therapy and no distant metastasis from 1st post-treatment WBS (post RxWBS). On multivariate analysis, stage I tumor and stimulated serum Tg level at 1st dose of radioiodine therapy $<30 \mathrm{ng} / \mathrm{mL}$ were the significant prognostic factors that increased disease-free rate by 1.73 times and 2.60 times, respectively (P-value $<0.05)$. Conclusions: Factors affecting the outcome of radioiodine therapy in our study were age, stage, risk of recurrence by histopathology, unifocal tumor involvement and 1st postRxWBS findings. From these factors, stage I tumor and stimulated serum Tg level at 1st dose of radioiodine therapy were independent prognostic factors that substantial increase the disease-free rate.
\end{abstract}

Keywords: Differentiated thyroid carcinoma - radioiodine therapy - disease-free status

Asian Pac J Cancer Prev, 16 (2), 737-740

\section{Introduction}

Many studies about predictive variables for outcome of radioactive iodine (RAI) therapy in differentiated thyroid carcinoma (DTC) have been established (D'Avanzo et al., 2004; Voutilainen et al., 2003; Davis et al., 1995; Hay et al., 1993; Byar et al., 1979;). All provided useful prognostic information; however, the results were various. The reasons were possible due to different criteria for diagnosis of disease-free status and different criteria for each prognostic factor in each study. The main goal of this study was to assess the significant prognostic factor that increased disease-free rate using the criteria of the revised American thyroid association management guideline for patients with thyroid nodules and DTC (ATA guideline, 2009) (Cooper et al., 2009).

\section{Materials and Methods}

\section{Patients}

From all patients who were received $1^{\text {st }}$ dose of RAI therapy after thyroidectomy at nuclear medicine division, Ramathibodi Hospital, Mahidol University, Bangkok, Thailand, from December 2003 to January
2012, we included 256 patients who have complete histopathological details of the tumor and follow-up time at least 1 year. The 256 patients (215 females, 41 males) were underwent total thyroidectomy (TTD) or near total thyroidectomy (near TTD) or complete thyroidectomy 6-8 weeks before RAI therapy.

Hospital records of 256 patients were reviewed for the treatment outcomes and the following predictive variables for outcome: gender, age at $1^{\text {st }}$ RAI therapy, stage, risk group of recurrence, unifocal/multifocal tumor involvement, stimulated serum $\mathrm{Tg}$ at $1^{\text {st }} \mathrm{RAI}$ therapy and $1^{\text {st }}$ postRxWBS findings.

Tumor staging was according to the sixth edition AJCC/UICC TNM classification (Sobin et al., 2002). Risk of recurrence was defined by pathological report as low, intermediate and high risk, in accordance with the Revised American Thyroid Association Management Guideline for Patients with Thyroid Nodules and Differentiated Thyroid Cancer 2009 (not include postRx WBS findings) (Cooper et al., 2009). Low risk patients have all of the following characteristics: all macroscopic tumors has been resected, no tumor invasion of locoregional tissues or vascular structures and the tumor does not have aggressive histology. 


\section{Radioactive iodine therapy and postRx WBS}

Radioactive iodine (RAI) therapy was performed 6 to 10 weeks after the operation. Blood was tested for stimulated serum thyroglobulin ( $\mathrm{Tg}$ ), antiTg antibody and TSH before RAI therapy as well as radiographic images to find evidence of distant metastasis.

The average RAI dose was $5.55 \mathrm{GBq}(150 \mathrm{mCi})$ to ablate thyroid remnant and to cure lymph node metastases and lung metastases. The activity was higher for bone metastases (7.40 GBq, $200 \mathrm{mCi}$ ).

A postRxWBS was performed 5-14 days after RAI therapy. Whole body planar scintigraphy was acquired using a dual-head gamma camera (Philips, FORTE, ADAC laboratory) until January 2011. SPECT images were acquired and processed using same dual-head gamma camera. Non-contrast CT scan using 16 slices CT scan (Philips MX 8000 CT scanner) was acquired at the area of equivocal lesion seen on planar images. After January 2011, infinia VC Hawkeye7, GE, SPECT/CT machine was subsequently used for both planar and SPECT/CT images. We graded the findings obtained into negative WBS, locoregional disease (uptake at thyroid bed and/ or cervical LN) and distant metastasis (abnormal uptake at other sites with or without uptake at thyroid bed and/ or cervical LN)

\section{Follow-up}

Patients were scheduled to investigate for disease status within 6 months after RAI therapy. All patients received thyroxin suppression: TSH level below $0.1 \mathrm{mU} / \mathrm{L}$ for intermediate and high risk patients and 0.1-0.5 mU/L for low risk patients (Cooper et al., 2009).

Patients were also submitted to physical examination, serum Tg and antiTg antibody. Diagnostic WBS following thyroid hormone withdrawal as well as stimulated serum $\mathrm{Tg}$, antiTg antibody and neck ultrasonography were obtained 6-12 months after RAI therapy for patients who had only locoregional disease. Patients with distant metastases were appointed to other treatment methods or next time of RAI therapy.

\section{Treatment outcomes}

The patients were considered in disease-free status by the criteria of the revised American thyroid association management guidelines for patients with thyroid nodules and DTC (ATA guidelines, 2009) as no clinical evidence of tumor, no imaging evidence of tumor on a recent diagnostic WBS and neck ultrasonography and undetectable stimulated serum Tg levels in the absence of interfering antiTg antibody (Cooper et al., 2009).

We defined stimulated serum $\mathrm{Tg}<2 \mathrm{ng} / \mathrm{mL}$ as undetectable. The absence of interfering antiTg antibody is when antiTg antibody $<50 \mathrm{IU} / \mathrm{ml}$ according to previous study from our hospital (Sritara et al., 2008).

Survival analysis was performed on the STATA version 12. Time to disease-free status was estimated with Kaplan-Miere Method. Potential prognostic factors were evaluated in Cox univariate analysis and then in a multivariate Cox regression analysis. Significant was defined as $\mathrm{P}$ value $<0.05$.

\section{Results}

Table 1 shows characteristics of 256 DTC patients: $84 \%$ female, $16 \%$ male. Approximately half of the patients were in low risk group. Most of the patients were in stage I, about $68 \%$. One hundred and thirty-eight patients $(55 \%)$ were 45 years old or younger. All patients were received RAI therapy after total or near total or complete thyroidectomy and follow-up at least 1 year. Median follow-up time is 3.7 years.

Of the 256 patients, 175 patients $(68.4 \%)$ were in disease-free status with the overall disease-free rates at $1,1.5,2$ and 2.5 years were $26 \%, 50 \%, 65 \%$ and $73 \%$, respectively, respectively, estimated with Kaplan-Meir Method..

Potential prognostic factors for disease-free survival were evaluated in Cox univariate analysis (Table 2). Age 45 years old or younger, stage I tumor, low risk group by histopathology and unifocal tumor were associated with disease -free survival (P value $<0.05)$. Stimulated serum Tg level equal to $30 \mathrm{ng} / \mathrm{mL}$ or below and locoregional I-131 uptake from 1st post RxWBS (no distant metastasis) were also important prognostic factors for disease-free status. Table 2 also shows the incidence rate of disease-free status per year and the median time to disease-free status for each significant variable.

Percentage of disease-free status in female patients was higher than male and median time to disease-free status of

Table 1. Patient Characteristics

\begin{tabular}{|c|c|c|}
\hline Characteristic & No. of patients & $(\%)$ \\
\hline \multicolumn{3}{|l|}{ Gender } \\
\hline Male & 41 & $(16.0)$ \\
\hline Female & 215 & (84.0) \\
\hline \multicolumn{3}{|l|}{ Age } \\
\hline$\leq 45$ & 138 & $(54.9)$ \\
\hline$>45$ & 118 & (46.1) \\
\hline \multicolumn{3}{|l|}{ Histology } \\
\hline Papillary & 219 & (85.5) \\
\hline Follicular & 34 & (13.3) \\
\hline Hürthle & 3 & $(1.2)$ \\
\hline \multicolumn{3}{|l|}{ Stage } \\
\hline I & 174 & $(68.0)$ \\
\hline II & 42 & (16.4) \\
\hline III & 22 & $(8.6)$ \\
\hline IV & 18 & (7.0) \\
\hline \multicolumn{3}{|l|}{ Risk of recurrence } \\
\hline Low & 125 & (48.8) \\
\hline Intermediate/High & 131 & $(51.2)$ \\
\hline \multicolumn{3}{|c|}{ Number of tumor involvement } \\
\hline Unifocal & 200 & (78.1) \\
\hline Multifocal & 56 & (21.9) \\
\hline \multicolumn{3}{|c|}{ Stimulated serum Tg level at $1 \mathrm{st}$ RAI therapy $(\mathrm{ng} / \mathrm{mL})$} \\
\hline$\leq 30$ & 143 & (55.9) \\
\hline$>30$ & 113 & $(44.1)$ \\
\hline \multicolumn{3}{|l|}{$1^{\text {st }}$ postRxWBS findings } \\
\hline Locoregional uptake & 221 & $(86.3)$ \\
\hline Distant metastasis & 35 & (13.7) \\
\hline \multicolumn{3}{|l|}{ Number of RAI } \\
\hline 1 & 232 & (90.6) \\
\hline 2 & 12 & $(4.7)$ \\
\hline 3 & 9 & (3.5) \\
\hline$>4$ & 3 & $(1.2)$ \\
\hline
\end{tabular}


Table 2. Univariate Findings

\begin{tabular}{|c|c|c|c|}
\hline Variable & $\begin{array}{l}\text { Median } \\
\text { time } \\
\text { to disease- } \\
\text { free (year) }\end{array}$ & $\begin{array}{l}\text { Incidence } \\
\text { rate } \\
\text { of disease- } \\
\text { free/year }\end{array}$ & P-value \\
\hline \multicolumn{4}{|l|}{ Gender } \\
\hline Male & 1.6 & 0.38 & \multirow{2}{*}{0.24} \\
\hline Female & 1.4 & 0.41 & \\
\hline \multicolumn{4}{|l|}{ Age } \\
\hline$\leq 45$ & 1.2 & 0.46 & \multirow[t]{2}{*}{$<0.05$} \\
\hline$>45$ & 1.7 & 0.35 & \\
\hline \multicolumn{4}{|l|}{ Histology } \\
\hline Papillary & 1.4 & 0.4 & \multirow[t]{2}{*}{0.88} \\
\hline Follicular/Hürthle & 1.6 & 0.45 & \\
\hline \multicolumn{4}{|l|}{ Stage } \\
\hline I & 1.2 & 0.48 & \multirow[t]{2}{*}{$<0.05$} \\
\hline II-IV & 1.8 & 0.27 & \\
\hline \multicolumn{4}{|l|}{ Risk of recurrence } \\
\hline Low & 1.3 & 0.46 & \multirow[t]{2}{*}{$<0.05$} \\
\hline Intermediate/High & 2 & 0.36 & \\
\hline \multicolumn{4}{|c|}{ Number of tumor involvement } \\
\hline Unifocal & 1.3 & 0.44 & \multirow[t]{2}{*}{$<0.05$} \\
\hline Multifocal & 2 & 0.29 & \\
\hline \multicolumn{4}{|c|}{ Stimulated serum $\mathrm{Tg}$ level at $1 \mathrm{st} \mathrm{RAI}(\mathrm{ng} / \mathrm{mL})$} \\
\hline$\leq 30$ & 1.2 & 0.68 & \multirow[t]{2}{*}{$<0.05$} \\
\hline$>30$ & 2.1 & 0.25 & \\
\hline \multicolumn{4}{|l|}{$1^{\text {st }}$ postRxWBS findings } \\
\hline Locoregional uptake & 1.3 & 0.42 & \multirow[t]{2}{*}{$<0.05$} \\
\hline Distant metastasis & 3 & 0.23 & \\
\hline
\end{tabular}

Table 3. Multivariate Findings

\begin{tabular}{|c|c|c|}
\hline & HR $(95 \% \mathrm{CI})$ & P-value \\
\hline \multicolumn{3}{|l|}{ Age } \\
\hline$\leq 45$ & $1.05(0.70-1.56)$ & 0.84 \\
\hline$>45$ & 1 & \\
\hline \multicolumn{3}{|l|}{ Stage } \\
\hline I & $1.73(1.18-2.55)$ & $<0.05$ \\
\hline II-IV & 1 & \\
\hline \multicolumn{3}{|l|}{ Risk of recurrence } \\
\hline Low & $1.08(0.77-1.52)$ & 0.66 \\
\hline Intermediate/High & 1 & \\
\hline \multicolumn{3}{|c|}{ Number of tumor involvement } \\
\hline Unifocal & $1.37(0.86-2.15)$ & 0.18 \\
\hline Multifocal & 1 & \\
\hline \multicolumn{3}{|c|}{ Stimulated serum Tg level at $1 \mathrm{st}$ RAI $(\mathrm{ng} / \mathrm{mL})$} \\
\hline$\leq 30$ & $2.60(1.84-3.73)$ & $<0.05$ \\
\hline$>30$ & 1 & \\
\hline \multicolumn{3}{|l|}{$1^{\text {st }}$ postRxWBS findings } \\
\hline Locoregional uptake & $1.86(0.94-3.67)$ & 0.08 \\
\hline Distant metastasis & 1 & \\
\hline
\end{tabular}

female patients was shorter than male; however, this was not statistically significant $(\mathrm{P}$-value $=0.24)$

Table 3 shows multivariate analysis of significant variables. Stage I tumor and stimulated serum $\mathrm{Tg}$ were two independent variables that increased disease-free rate by 1.73 times and 2.60 times, respectively ( $\mathrm{P}$-value $<0.05)$.

\section{Discussion}

From the characteristic result, the percentage of female and male in our study are $84 \%$ and $16 \%$, respectively, almost similar to the result of retrospective analysis of thyroid cancer in China (Yumei Yang, 2011) but higher in female percentage than study in Iran (Khayamzadeh, $2011)$. Ratio of patients in two age groups ( $\leq 45$ year and $>45$ years) are not much different $(54.9 \%$ and $45.1 \%$, respectively). The most common cell type is papillary carcinoma $(85.5 \%)$, which is similar to the previous publish studies (Zaman, 2012 and Yumei Yang, 2011).

The main goal of this study was to assess the significant prognostic factor that increased disease-free rate using the criteria of the revised American thyroid association management guideline for patients with thyroid nodules and DTC. To this goal, we undertook both univariate and multivariate analyses to evaluate many prognostic factors in DTC patient group.

Stage I tumor by TNM staging system was one of the independent prognostic factors for disease-free status in our study, which is in agreement with the publish study (Sautter-Bihl, 2001). This was probably because stage I group was included patients with no distant metastases, some patients with small tumor size $(<2 \mathrm{~cm}$ with age $>$ 45 years old) and some patients with age $\leq 45$ years old. All of these were good prognostic factors for outcome.

Although there was a study concluded that the stimulated serum Tg level at $1^{\text {st }}$ RAI therapy may not determine risk of recurrence (Hasbek, 2014). Our study, in agreement with some studies (Lin et al., 1998; Verburg et al., 2005), shows that stimulated serum Tg level at $1^{\text {st }}$ RAI therapy was an another independent prognostic factor for successful RAI therapy. The previous study (Heemstra et al., 2007) suggested that cut-off point of stimulated serum Tg level for successful RAI therapy was $27.5 \mathrm{mcg} / \mathrm{L}$ (positive predictive value 98\%). In our series, cut-off point of stimulated serum $\mathrm{Tg}$ level at $1^{\text {st }} \mathrm{RAI}$ therapy for good outcome was $<30 \mathrm{ng} / \mathrm{mL}$.

Many literatures showed that age is a strong predictor of outcome in DTC patients (Sobin et al., 2002; Durante et al., 2006; Toniato et al., 2008; Tubiana et al., 1985). In this univariate analysis, age was also significant factor for disease-free status. Age $\leq 45$ years old showed good better outcome than $>45$ years old.

Number of the tumor is another interested factors. There was a study (Lang et al., 2006) which is suggested that patients with multifocal tumor have a lower survival rate than patients with unifocal tumor (Hazard ratio $=1.79$, $\mathrm{p}=0.048$ ). This finding is similar to our study that unifocal tumor was one of significant factor for disease-free status in univariate analysis.

Risk of recurrence was defined by histopathology of tumor, including presence of aggressive histology, vascular and capsular invasion and surgical margin status. For patient in the low risk group with tumor size less than $1 \mathrm{~cm}$, there was some controversies in use of RAI therapy as review by one study (Zaman et al., 2013). In our study, RAI was given to the patient in low risk group only who had tumor size more than $1 \mathrm{~cm}$. Our findings revealed that low risk group had better prognosis than intermediate and high risk. This result was similar to many publish studies (McConahey et al., 1986; Gemsenjager et al., 2001; Falvo et al., 2005; Lang et al., 2006).

No distant metastases from 1 st postRx WBS is also a significant factor in our univariate analysis, in accordance with the MACIS, AGES and EORTC systems. The prior 


\section{Kanungnij Thamnirat et al}

study (Lang et al., 2006) suggested that follicular thyroid cancer patients with distant metastases had significantly decreased survival rate (Hazard ratio $=5.25, \mathrm{p}=0.001)$. The other study (Durante et al., 2006) reported that survival rate in patients with macronodular pulmonary metastases or multiple bony metastases decreased to $14 \%$.

Our results in univariate analysis, in agreement with the MACIS, AGES, AMES and EORTC prognostic scoring systems (Hay et al., 1993; Davis et al., 1995; D'Avanzo et al., 2004), showed the importance of age at diagnosis, unifocal disease and low risk group by histopathology as significant prognostic factors. However, none of these factors independently improved outcome in multivariate analysis.

Our data shown that no significant differences in treatment outcome according to gender, agreed with the published study (Toniato et al., 2008). However, in disagreement with some studies (Tubiana et al., 1985 and Kim et al., 2008), which shown that male gender was a poor prognostic factor for treatment outcome.

\section{References}

Byar DP, Green SB, Dor P, et al (1979). A prognostic index for thyroid carcinoma: a study of the E.O.R.T.C. Thyroid cancer cooperative group. Eur J Cancer, 15, 1033-41.

Cooper DS, Doherty GM, Haugen BR, et al (2009). Revised American Thyroid Association management guidelines for patients with thyroid nodules and differentiated thyroid cancer. Thyroid, 19, 1167-214.

Davis NL, Bugis SP, McGregor GI, Germann E (1995). An evaluation of prognostic scoring systems in patients with follicular thyroid cancer. Am J Surg, 170, 476-80.

Durante C, Haddy N, Baudin E, et al (2006). Long-term outcome of 444 patients with distant metastases from papillary and follicular thyroid carcinoma: benefits and limits of radioiodine therapy. J Clin Endocrinol Metab, 91, 2892-9.

D'Avanzo A, Ituarte P, Treseler P, et al (2004). Prognostic scoring systems in patients with follicular thyroid cancer: a comparison of different staging systems in predicting the patient outcome, Thyroid, 14, 453-8.

Falvo L, Catania A, D'Andrea V, et al (2005). Prognostic importance of histologic vascular invasion in papillary thyroid carcinoma. Ann Surg, 241, 640-6.

Gemsenjäger E, Heitz PU, Seifert B, et al (2001). Differentiated thyroid carcinoma, Follow-up of 264 patients from one institution for up to 25 years. Swiss Med Wkly, 131, 157-63.

Hasbek Z, Turgut B, Kilicli F, et al (2014). Importance of postoperative stimulated thyroglobulin level at the time of $131 \mathrm{i}$ ablation therapy for differentiated thyroid cancer. Asian Pac J Cancer Prev, 15, 2523-7.

Hay ID, Bergstralh EJ, Goellner JR, et al (1993). Predicting outcome in papillary thyroid carcinoma: development of a reliable prognostic scoring system in a cohort of 1779 patients surgically treated at one institution during 1940 through 1989. Surgery, 114, 1050-7.

Heemstra KA, Liu YY, Stokkel M, et al (2007). Serum thyroglobulin concentrations predict disease-free remission and death in differentiated thyroid carcinoma. Clin Endocrinol, 66, 58-64.

Kim TY, Hong SJ, Kim JM, et al (2008). Prognostic parameters for recurrence of papillary thyroid microcarcinoma. $B M C$ Cancer, 8, 296.

Khayamzadeh M, Khayamzadeh M, Tadayon N, et al (2011). Survival of thyroid cancer and social determinants in Iran,
2001-2005, Asian Pacific J Cancer Prev, 12, 95-8.

Lang BH, Lo CY, Chan WF, et al (2006). Prognostic factors in papillary and follicular thyroid carcinoma: their implications for cancer staging. Ann Surg Onc, 14, 730-8.

Lin JD, Kao PF, Chao TC (1998). The effects of radioactive iodine in thyroid remnant ablation of well differntiated thyroid carcinoma. Br J Radiol, 71, 307-13.

McConahey WM, Hay ID, Woolner LB, et al (1986). Papillary thyroid cancer treated at the Mayo Clinic 1946 through 1970: initial manifestations, pathologic findings, therapy and outcomes. Mayo Clinic Proc, 61, 978-96.

Sautter-Bihl ML, Raub J, Hetzel-Sesterheim M, Heinze HG (2001). Differentiated thyroid cancer: prognostic factors and influence of treatment on the outcome in 441 patients. Strahlenther Onkol, 177, 125-31.

Sobin LH, Wittekind CH (2002). UICC: TNM Classification of Malignant Tumors 6th ed. NewYork: Wiley-Liss.

Sritara C, Taeshineetanakul P, Kositwatanarerk A, et al (2008) Cutoff Point for Serum TgAb by ICMA Technique in Patients with Differentiated Thyroid Carcinoma (DTC). http:// www2.ra.mahidol.ac./rar/infor_reserch_rama/Annual\%20 Absrtract/ MeetInter2008.pdf.

Toniato A, Boschin I, Casara D, et al (2008). Papillary thyroid carcinoma: factors influencing recurrence and survival. Ann Surg Oncol, 15, 1518-22.

Tubiana M, Schlumberger M, Rougier P, et al (1985). Long-term results and prognostic factors in patients with differentiated thyroid carcinoma. Cancer, 55, 794-804.

Verburg FA, de Keizer B, Lips CJ, et al (2005). Prognostic significance of successful ablation with radioiodine of differentiated thyroid cancer patients. Eur J Endocrinol, 152, 33-7.

Yang Y, Li Q, Guo L, et al (2011). A Retrospective Analysis of Thyroid Cancer in China. Asian Pac J Cancer Prev, 12, 2245-9.

Zaman MU, Fatima N, Padhy, et al (2013). Controversies about radioactive iodine-131 remnant ablation in low risk thyroid cancers: are we near a consensus? Asian Pac J Cancer Prev, 14, 6209-13.

Zaman MU, Fatima N, Sajjad Z, et al (2012). Threshold primary tumour sizes for nodal and distant metastases in papillary and follicular thyroid cancers. Asian Pac J Cancer Prev, 13, 2473-6. 